\title{
Autocatalytic Self-Sorting in Biomimetic Polymer
}

\author{
Kaiyi Zhou, Hui Cao, Pan Gao, Zhigang Cui, Yi Ding, and Yuanli Cai*
}

State and Local Joint Engineering Laboratory for Novel Functional Polymeric Materials, Jiangsu

Key Laboratory of Advanced Functional Polymer Design and Application, Suzhou Key Laboratory of Macromolecular Design and Precision Synthesis, College of Chemistry, Chemical Engineering and Materials Science, Soochow University, Suzhou 215123, China

\section{Supporting Information}

Materials. Cystamine methacrylamide hydrochloride (CysMA) ${ }^{1}$ and 2-hydroxypropylmethacrylamide (HPMA) ${ }^{2}$ monomers, sodium phenyl-2,4,6-trimethylbenzoylphosphinate (SPTP) $)^{3,4}$ initiator, and 4-cyano-4-ethylsulfanylthiocarbonylsulfanylpentanoic acid (CEP) $)^{5,6}$ chain transfer agent were synthesized according to literature procedures. $\mathrm{CuCl}_{2} \cdot 2 \mathrm{H}_{2} \mathrm{O}(99.999 \%)$ was purchased from Aladdin; deuterium oxide $\left(\mathrm{D}_{2} \mathrm{O}, 99.8 \% \mathrm{D}\right)$, deutero-chloric acid $\left(\mathrm{DCl}, 99.5 \% \mathrm{D}, 20 \%\right.$ in $\left.\mathrm{D}_{2} \mathrm{O}\right)$, and sodium deuteroxide $\left(99.5 \% \mathrm{D}, 40 \%\right.$ in $\mathrm{D}_{2} \mathrm{O}$ ) from J\&K; methanol, 2-butoxyethanol, $\mathrm{NaOH}$, di-tert-butyldicarbonate and trimethylamine from Sinopharm; these agents were used as received. Deionized water $\left(\mathrm{R}>18.2 \mathrm{M} \Omega \mathrm{cm}^{-1}\right)$ was used for all the synthesis and characterization.

Visible light. A mercury lamp was used as an irradiation source, in which ultraviolet light above $\lambda_{\mathrm{em}}=400 \mathrm{~nm}$ was removed using JB400 filters. The intensity of visible light decreased to $\mathrm{I}_{420 \mathrm{~nm}}=$ $0.20 \mathrm{~mW} \mathrm{~cm}^{-2}(\sim 5 \%$ sunlight in Suzhou, China), as determined using a UV-A radiometer. 
Synthesis of PHPMA macro-CTA. HPMA monomer ( $8.015 \mathrm{~g}, 56 \mathrm{mmol})$, CEP chain transfer agent $(0.074 \mathrm{~g}, 0.28 \mathrm{mmol})$ and SPTP initiator $(0.022 \mathrm{~g}, 71 \mu \mathrm{mol})$ were dissolved in the mixture of 2-butoxyethanol and water (30:70, wt./wt.; $2.40 \mathrm{~g})$ in a 50-mL round-bottom flask. The flask was sealed and immersed into a thermostatic water bath at $25^{\circ} \mathrm{C}$, bubbled with argon gas in the dark for $60 \mathrm{~min}$, and then irradiated with visible light for $75 \mathrm{~min} .{ }^{1} \mathrm{H}$ NMR: $56 \%$ conversion. The reaction solution was diluted in methanol, precipitated into excess of acetone, washed with acetone, and dried in vacuum oven at $30^{\circ} \mathrm{C}$ for 3 days. Yield: $4.20 \mathrm{~g}, 50 \% .{ }^{1} \mathrm{H}$ NMR: $\mathrm{DP}_{\mathrm{HPMA}}=107$; SEC: $M_{\mathrm{n}}=15.3 \mathrm{kDa}, \mathrm{PDI}=1.12$, and thus termed as PHPMA $_{107}$ macro-CTA.

Synthesis of PHPMA-b-PCysMA. PHPMA 107 macro-CTA (0.670 g, $43.73 \mu \mathrm{mol})$, CysMA monomer $(1.124 \mathrm{~g}, 4.37 \mathrm{mmol})$ and SPTP initiator $(4 \mathrm{mg}, 10.93 \mu \mathrm{mol})$ were dissolved in water $(7.50 \mathrm{~g})$ in a $25-\mathrm{mL}$ flask. The solution was adjusted to $\mathrm{pH} 3.5$ using hydrochloric acid (1.40 M). The flask was sealed and immersed into a water bath at $25^{\circ} \mathrm{C}$. The solution was bubbled with argon gas in the dark for $60 \mathrm{~min}$, and then irradiated with visible light for $2 \mathrm{~h} .{ }^{1} \mathrm{H}$ NMR: $80 \%$ conversion. The solution was dialyzed against water at $\mathrm{pH} 3.0$ using dialysis membrane (MWCO=1.0 kDa), and lyophilized in Labconco Freezone2.5L freeze-drier. Yield: 1.40 g, 78\%. ${ }^{1} \mathrm{H}$ NMR: PHPMA ${ }_{107-}$ $b$-PCysMA80; SEC: $M_{\mathrm{n}}=33.4 \mathrm{kDa}, \mathrm{PDI}=1.11$.

Polymer Characterization. Structural intactness and degree of polymerization (DP) of PHPMA and the block copolymer was determined by ${ }^{1} H$ NMR Spectroscopy on an INOVA $400 \mathrm{MHz}$ NMR instrument at $25^{\circ} \mathrm{C}$. Size Exclusion Chromatography (SEC) was used to determine the molecular weight $\left(M_{\mathrm{n}}\right)$ and polydispersity index (PDI, $\left.M_{\mathrm{w}} / M_{\mathrm{n}}\right)$ on a PL-GPC220 integrated system fitted with a refractive index detector and a set of SEC columns $(2 \times$ PLGel MIXED-B $+1 \times$ PLGel MIXEDD). DMF that contained $10.0 \mathrm{mM} \mathrm{LiBr}$ was filtered and used as eluent. Poly(methyl methacrylate) (PMMA, Agilent, 1.95 1048 kDa) were used for calibration. Calibration and analysis were carried 
out at a $1.0 \mathrm{~mL} \mathrm{~min}^{-1}$ flow rate and $80^{\circ} \mathrm{C} . \mathrm{NH}_{3}{ }^{+}$-motifs were reacted with di-tert-butyldicarbonate according to the literature procedures, ${ }^{4}$ to circumvent the absorption onto the column materials.
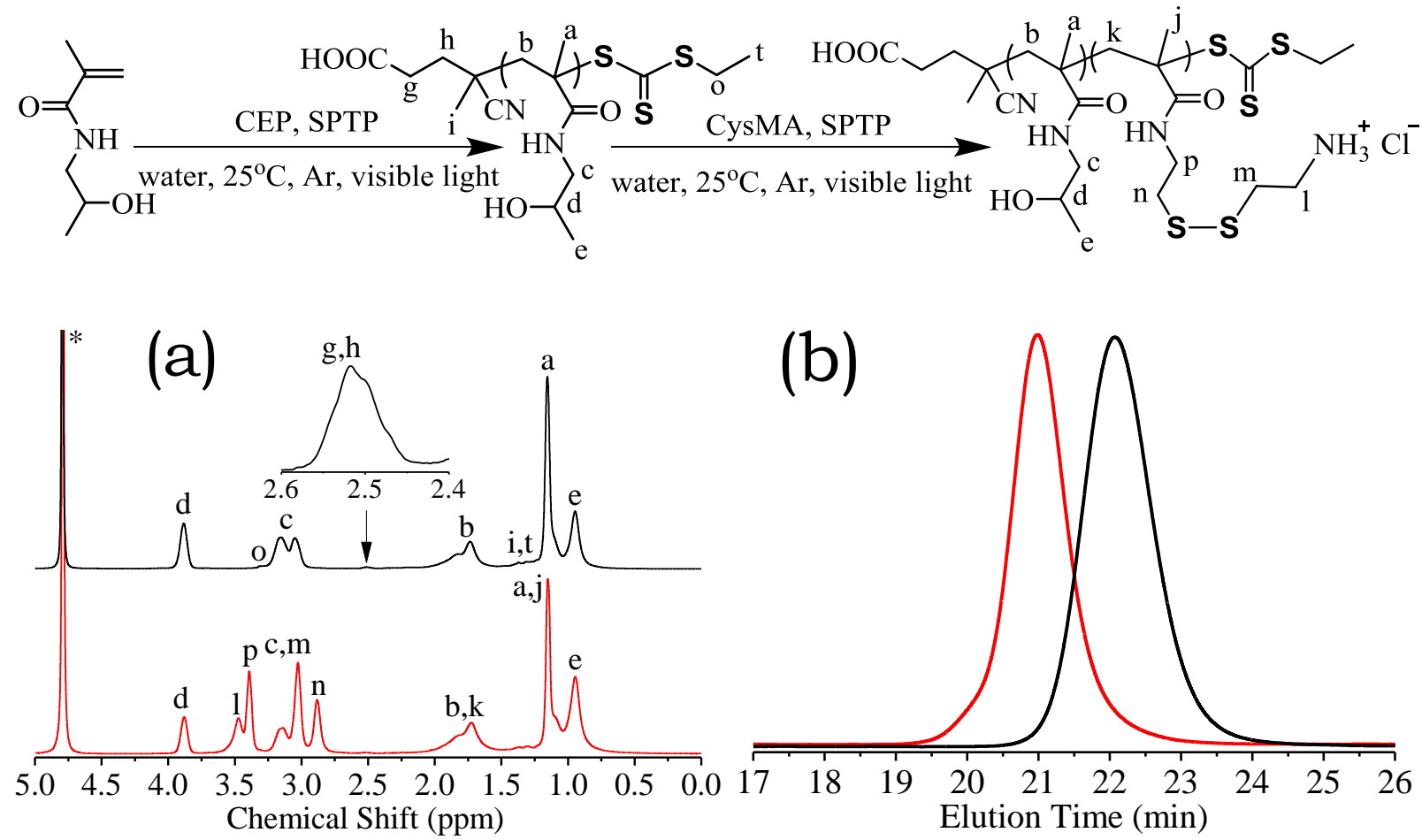

Figure S1. (a) ${ }^{1}$ H NMR spectra, (b) SEC traces of PHPMA (black) and PHPMA- $b$-PCysMA (red) that were synthesized by RAFT in acidic water at $\mathrm{pH} 3.5$ under visible light irradiation at $25^{\circ} \mathrm{C}$.

As shown in the top spectrum of Figure S1a, the monomer and other impurities are undetectable. Moreover, the integration ratio $I_{\mathrm{d}} / I_{\mathrm{c}} / I_{\mathrm{b}} / I_{\mathrm{a}+\mathrm{e}}=1 / 2 / 2 / 6$ is consistent with proton ratio in HPMA units, indicating the intactness of as-synthesized PHPMA. A degree of polymerization (DPHPMA) of 107 was determined according to $\mathrm{DP}_{\mathrm{HPMP}}=\left(4 \times I_{\mathrm{d}}\right) / I_{\mathrm{g}+\mathrm{h}}$, in which $I_{\mathrm{d}}$ and $I_{\mathrm{g}+\mathrm{h}}$ are the integral signals $\mathrm{C} \underline{\mathbf{H}}\left(\mathrm{CH}_{3}\right) \mathrm{OH}$ in HPMA units and $\underline{\mathrm{C}}_{2} \mathrm{C}_{2} \mathrm{COOH}$ at $\mathrm{CEP}$ chain-ends (inset). Intactness of CysMA units was confirmed by the integral signals $l, p$ identical to those of $m, n\left(I_{\mathrm{m}+\mathrm{n}}=I_{\mathrm{c}+\mathrm{m}+\mathrm{n}}-2 \times I_{\mathrm{d}}\right)$ (bottom spectrum). A DP ${ }_{\text {CysMA }}$ of 80 was determined according to $\mathrm{DP}_{\mathrm{CysMA}}=\mathrm{DP}_{\mathrm{HPMA}} \times \mathrm{I}_{1+\mathrm{p}} /\left(4 \times \mathrm{I}_{\mathrm{d}}\right)$. As shown in Figure S1b, these SEC traces are unimodal and symmetrical. Chain extension led to 
the clear shift to higher molecular weight. Analysis indicates $M_{\mathrm{n}}=15.3 \mathrm{kDa}$ and PDI $=1.12$ of the PHPMA $_{107}$ macro-CTA; $M_{\mathrm{n}}=33.4 \mathrm{kDa}$ and PDI $=1.11$ of PHPMA $_{107}-b$-PCysMA 80 sample.

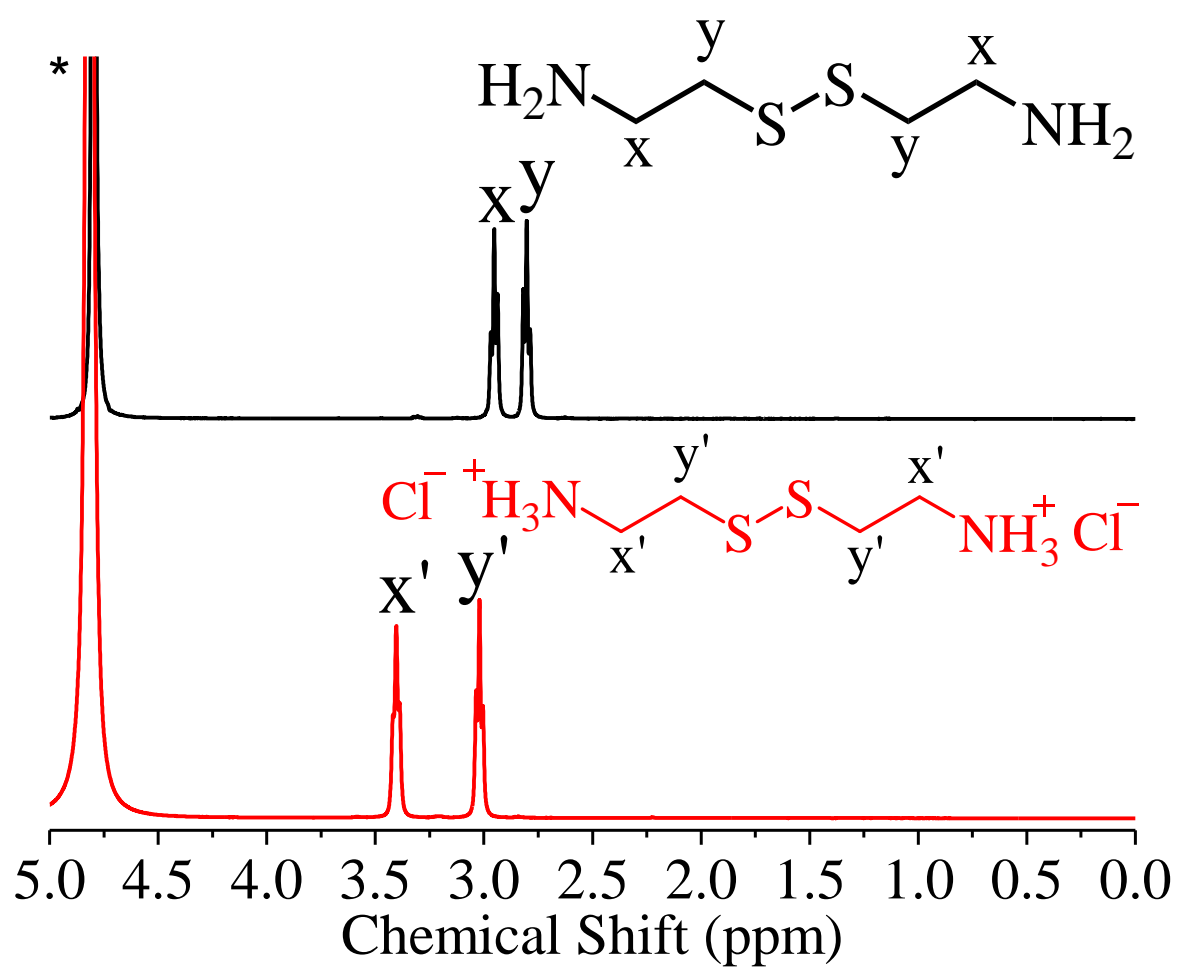

Figure S2. ${ }^{1} \mathrm{H}$ NMR spectra of commercial cystamine hydrochloride (99\%) in $\mathrm{D}_{2} \mathrm{O}$ after adjusted separately to $\mathrm{pH} 10.5$ using $\mathrm{NaOD}$ (top) and $\mathrm{pH} 3.0$ using $\mathrm{DCl}$ (bottom).

${ }^{1} \mathrm{H}$ NMR of cystamine hydrochloride in $\mathrm{D}_{2} \mathrm{O}$ at $\mathrm{pH} 3.0(400 \mathrm{MHz}, \delta, \mathrm{ppm}): 3.40(4 \mathrm{H}$, $\left.\mathrm{CH}_{2} \underline{\mathrm{C}}_{2} \mathrm{NH}_{3}{ }^{+}\right), 3.04\left(4 \mathrm{H}, \underline{\mathrm{C}}_{2} \mathrm{CH}_{2} \mathrm{NH}_{3}{ }^{+}\right)$.

${ }^{1} \mathrm{H}$ NMR of cystamine molecules in $\mathrm{D}_{2} \mathrm{O}$ at $\mathrm{pH} 10.5$ (400 MHz, $\left.\delta, \mathrm{ppm}\right): 2.95\left(4 \mathrm{H}, \mathrm{CH}_{2} \mathrm{C}_{2} \mathrm{NH}_{2}\right)$, $2.80\left(4 \mathrm{H}, \mathrm{C}_{2} \mathrm{CH}_{2} \mathrm{NH}_{2}\right)$. 


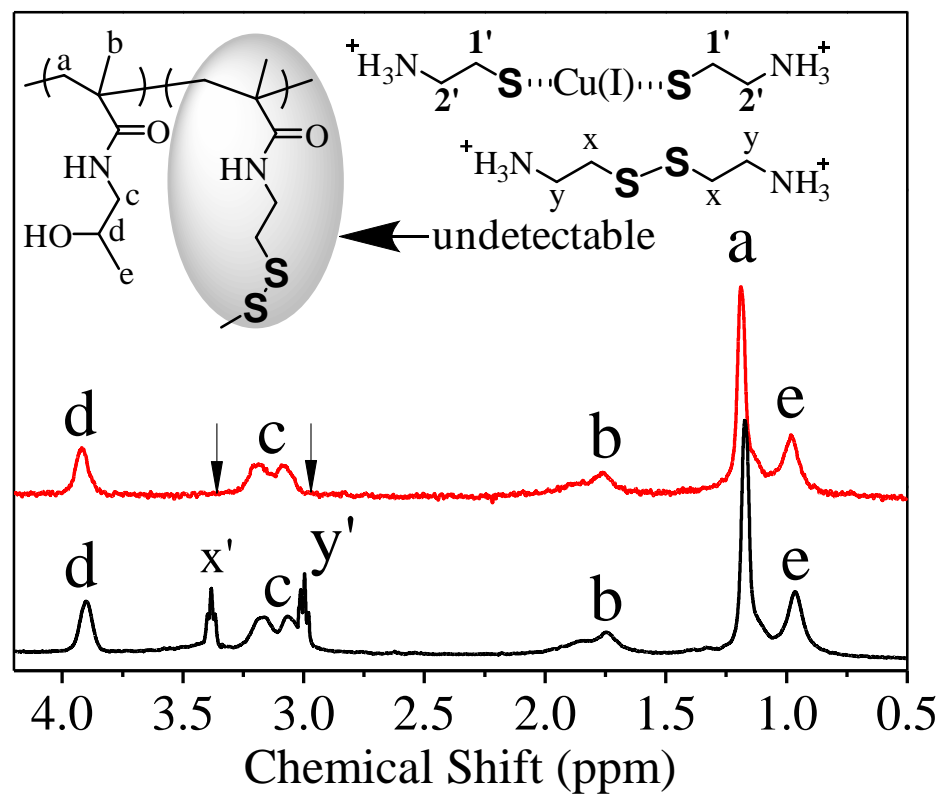

Figure S3. (a) ${ }^{1} \mathrm{H}$ NMR spectra of the polymer sample after reaction in $\mathrm{D}_{2} \mathrm{O}$ at $\mathrm{pH} 10.5$ for $24 \mathrm{~h}$ and adjusted to $\mathrm{pH} 3.0$ (bottom); that after dialyzed, lyophilized and re-dispersed in $\mathrm{D}_{2} \mathrm{O}$ at $\mathrm{pH} 3.0$ (top).

$$
\text { Conversion }=\frac{I_{\left(c+x^{\prime}+y^{\prime}\right)}-2 \times I_{d}}{4 \times I_{d}} \times \frac{107}{80} \times 100 \%
$$

As showed in the bottom spectrum in Figure S3, signals $x^{\prime}, y^{\prime}$ in cystamine molecules are discernible with an integral ratio $\left(\mathrm{I}_{\mathrm{d}} / \mathrm{I}_{\mathrm{c}+x^{\prime}+y^{\prime}}\right)$ of $1 / 4$. Therefore, a conversion of $67 \%$ was evaluated according to eq. S1. Cystamine molecules were removed by dialysis, as judged by disappearing of the signals (top spectrum). These results indicate that the as-generated cystamine molecules were released into solution. Moreover, the detectable PHPMA and undetectable PCysMA block after dialysis was observed, as judged by an integral ratio $\mathrm{I}_{\mathrm{d}} / \mathrm{I}_{\mathrm{c}} / \mathrm{I}_{\mathrm{b}} / \mathrm{I}_{\mathrm{a}+\mathrm{e}}$ of 1:2:2:6 (in good agreement with those in HPMA units) whereas the disappearance of signals in CysMA units. These results indicate that the residual CysMA units $(33 \%)$ are inaccessible to aqueous medium due to the encapsulation in the hydrophobic domains. Otherwise, signals in the unreacted CysMA units at $\mathrm{pH} 3.0$ would be detectable because of the ionization into $\mathrm{NH}_{3}{ }^{+}$-motifs. 


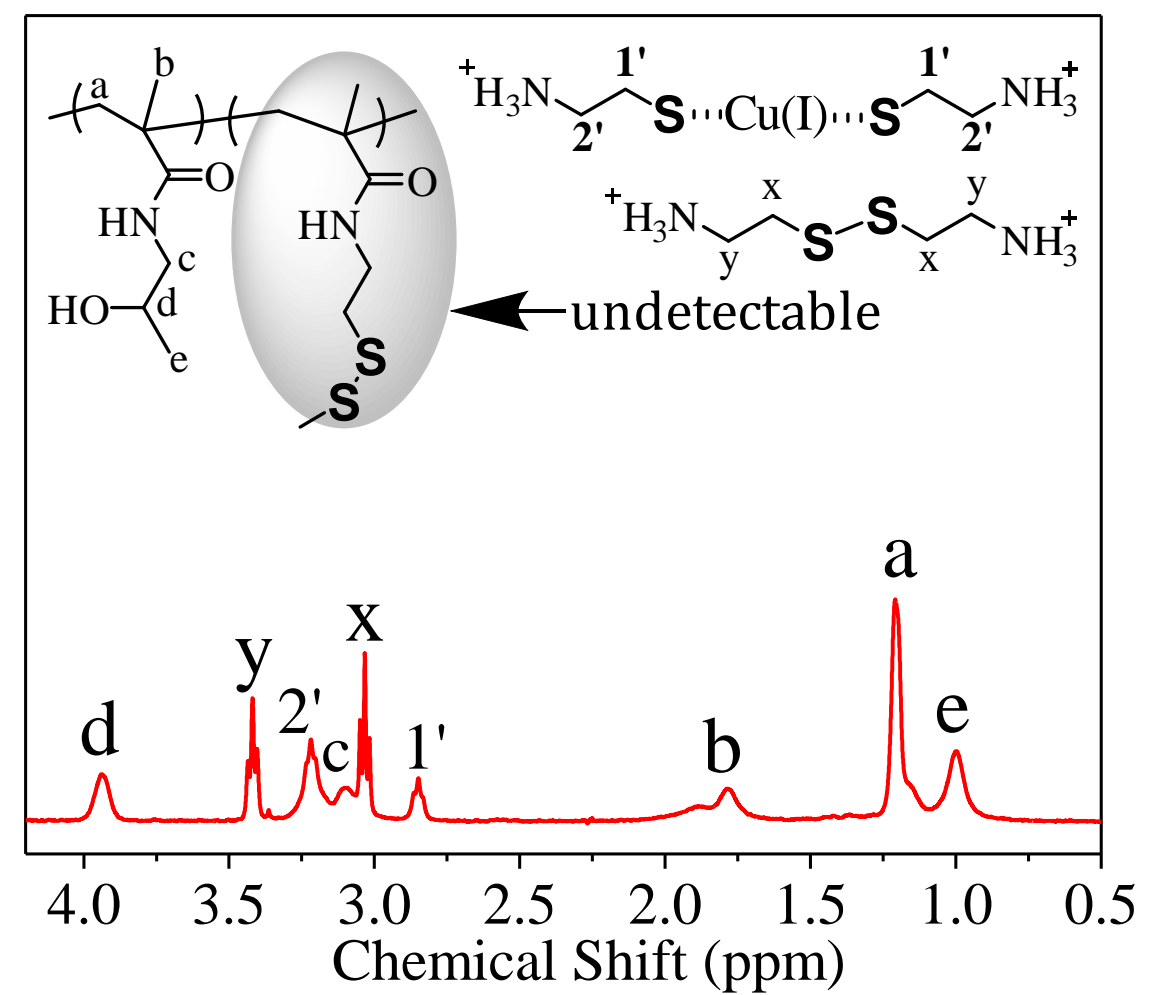

Figure S4. ${ }^{1} \mathrm{H}$ NMR spectra of the solution in the presence of copper ions at a $[\mathrm{CysMA}]_{0} /[\mathrm{Cu}(\mathrm{II})]_{0}$ $=4$ after reaction in $\mathrm{D}_{2} \mathrm{O}$ at $\mathrm{pH} 8.8$ for $24 \mathrm{~h}$ and adjusted back to $\mathrm{pH} 3.0$.

$$
\text { Conversion }=\frac{I_{\left(1^{\prime}+2^{\prime}+(+x+y)\right.}-2 \times I_{d}}{4 \times I_{d}} \times \frac{107}{80} \times 100 \%
$$

As showed in Figure S4, signals $x, y$ in cystamine molecules and those in intermediate cuprous complexes $\left(1^{\prime}, 2^{\prime}\right)$ are discernible with an integral ratio $\left(\mathrm{I}_{\mathrm{d}} / \mathrm{I}_{\mathrm{c}^{+}+\mathrm{x}+\mathrm{y}+1^{\prime}+2^{\prime}}\right)$ of $1 / 5$. Accordingly, $100 \%$ conversion was evaluated according to eq. S2. The results demonstrate that autocatalytic disulfide exchange in the presence of copper ions resulted in an ideal self-sorting in the reactive block with essentially $100 \%$ conversion. 


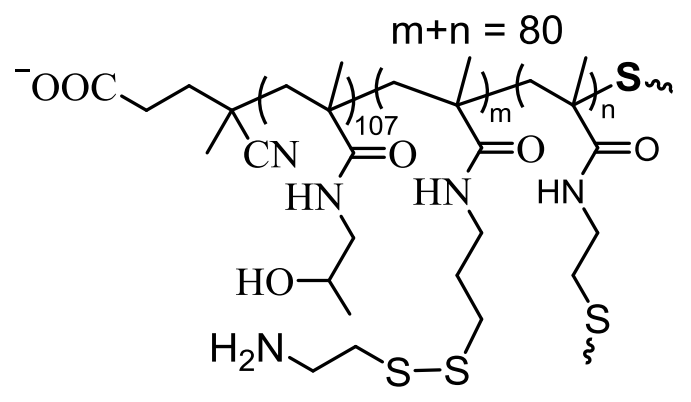

Scheme S1. Molecular Structure of Reacted Block Copolymer. Herein, $n$ is Number of Reacted CysMA Units and $m$ is that of Residual CysMA Units.

$$
\frac{C}{N}=\frac{12 \times\left(7 \times D P_{H P M A}+9 \times m+6 \times n+6\right)}{14 \times\left(1 \times D P_{H P M A}+2 \times m+n+1\right)}
$$

The reaction solutions in the absence of copper ions at $\mathrm{pH} 10.5$ and presence of copper ions at $\mathrm{pH} 8.8$ were separately dialyzed against water at $\mathrm{pH} 3.0$ and lyophilized under reduced pressure. These samples along with initial polymer were characterized using elemental analysis. The result (tested: $\mathrm{C} / \mathrm{N}=4.488)$ of as-synthesized sample is in good agreement with theoretical value $(\mathrm{C} / \mathrm{N}$ $=4.470$ ), which confirms intactness of this block copolymer. Moreover, reaction conversion was determined according to eq. S3 and Scheme S1. Accordingly, 65\% CysMA units participated in

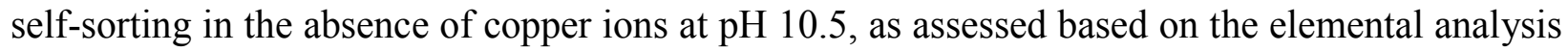
result $(\mathrm{C} / \mathrm{N}=5.236) ; 98 \%$ CysMA units participated in self-sorting in the presence of copper ions at $\mathrm{pH} 8.8$, as assessed according to the elemental result of $\mathrm{C} / \mathrm{N}=5.603$.

\section{REFERENCES}

1. Shi, H.; Zhou, K.; Yu, Q.; Cui, Z.; Jiang, Y.; Lu, X.; Cai, Y. Programmable Self-Assembly of a Cystamine-Block Copolymer in Response to $\mathrm{pH}$ and Progressive Reduction-IonizationOxidation. Polym. Chem. 2015, 6, 7455-7463. 
2. Scales, C. W.; Vasilieva, Y. A.; Convertine, A. J.; Lowe, A. B.; McCormick, C. L. Direct, Controlled Synthesis of the Nonimmunogenic, Hydrophilic Polymer, Poly(N-(2-hydroxypropyl)methacrylamide) via RAFT in Aqueous Media. Biomacromolecules 2005, 6, 1846-1850.

3. Bronstert, B.; Henne, A.; Hesse, A.; Jacobi, M.; Wallbillich, G., Acylphosphine Compounds and Their Use as Photoinitiators. Patent US 4719297, 1988.

4. Tong, J.; Shi, Y.; Liu, G.; Huang, T.; Xu, N.; Zhu, Z.; Cai, Y. Visible Light Mediated Fast Iterative RAFT Synthesis of Amino-Based Reactive Copolymers in Water at $20^{\circ} \mathrm{C}$. Macromol. Rapid Commun. 2013, 34, 1827-32.

5. Xu, X. W.; Smith, A. E.; Kirkland, S. E.; McCormick, C. L. Aqueous RAFT Synthesis of pH-Responsive Triblock Copolymer mPEO-PAPMA-PDPAEMA and Formation of Shell CrossLinked Micelles. Macromolecules 2008, 41, 8429-8435.

6. Convertine, A. J.; Benoit, D. S.; Duvall, C. L.; Hoffman, A. S.; Stayton, P. S. Development of a Novel Endosomolytic Diblock Copolymer for siRNA Delivery. J. Control. Release 2009, 133, $221-229$. 